\title{
Dados abertos e ciência aberta: como as universidades federais brasileiras se apresentam nesse horizonte ${ }^{1}$
}

\author{
Ana Cristina Gomes Santos \\ Universidade Federal de Rural de Amazônia, Belém, Pará, Brasil \\ Judite Antonieta Gonçalves de Freitas \\ Universidade Fernando Pessoa, Porto, Portugal
}

ORIGINAL

\begin{abstract}
Resumo
Objetivo. O presente estudo visa identificar as universidades federais brasileiras que já implantaram a Política Brasileira de Dados Abertos a partir do decreto n. 8.777/2016, quantas já estão com dados abertos no portal nacional, e, quais critérios estão seguindo para construção de seus Planos de Dados Abertos (PDA), se há indicação de evolução para Ciência Aberta, vertente da transparência pública que está comprometida com a divulgação de dados das pesquisas desenvolvidas nas instituições acadêmicas no Brasil.

Método. A investigação assentou na pesquisa bibliográfica de artigos científicos de referência sobre o tema e as técnicas de análise documental para estudo dos planos de dados abertos disponíveis no portal de dados (dados.gov.br) para identificar que tipo de informações as universidades estão disponibilizando.

Resultados. De acordo com os resultados, foi possível constatar que há dificuldades por parte das instituições em cumprir com a política nacional uma vez que apenas $42 \%$ das universidades públicas brasileiras já estão com dados no portal. Em algumas delas, identifica-se que o cronograma de abertura dos dados não foi colocado em prática em sua totalidade, a maioria $58 \%$ ainda não atendem o que preconiza a política .

Conclusões. O indicador de mais da metade das universidades fora do portal de dados nacional aponta que os objetivo da política comprometem a transparência pública dessas organizações. Na perspectiva de encontrar nos PDAs informação que indicassem a evolução da divulgação de Dados Abertos para a Ciência Aberta não foi possível identificar nenhuma informação para essa evolução na transparência das instituições, sugere-se um estudo aprofundado sobre esse tema em todas as universidades federais brasileiras.
\end{abstract}

Palavras-chave:

Ciência aberta; Dados abertos; Governo eletrônico; Instituições públicas de ensino superior.

\section{Open data and open science: how brazilian federal universities present themselves in this horizon}

\begin{abstract}
Objective. The present study aims to identify the Brazilian Federal Universities that have already implemented the Brazilian Open Data Policy from Decree n. 8.777 / 2016, how many are already with data open in the national portal, and, what criteria are being followed to build their Open Data Plans (PDA), if there is an indication of evolution for Open Science, public transparency strand that is committed to dissemination of research data developed in academic institutions in Brazil.

Method. The research was based on the bibliographic research of reference scientific articles on the subject and techniques of documentary analysis to study the open data plans available in the data portal (data.gov.br) to identify what kind of information the universities are making available.

Results. According to the results, it was possible to verify that there are difficulties on the part of the institutions to comply with the national policy since only $42 \%$ of the Brazilian public universities are already with data in the portal. In some of them, it is identified that the schedule for opening the data was not put into practice in its entirety, most $58 \%$ still do not comply with what the policy advocates.

Conclusions. The indicator of more than half of the universities outside the national data portal points out that the policy objective compromises the public transparency of these organizations. In the perspective of finding in the PDAs information that indicate the evolution of the Open Data for Open Science, it was not possible to identify any information for this evolution in the transparency of the institutions, it is suggested an in-depth study on this subject in all Brazilian federal universities.
\end{abstract}

Keywords:

Electronic government; Open data; Open science; Public institutions of higher education.

${ }^{1}$ Texto originalmente aceito para apresentação no EDICIC 2019 que acontece entre os dias 8 e 11 de julho em Barcelona, dentre as politicas do evento as comunicaçõe devem ser submetidas a uma revista que aceite preprint. Desta forma este trabalho está aberto a contribuições. 


\section{Introdução}

O Estado brasileiro com características singulares regionais de cunho geográfico e social apresenta-se, também, da mesma forma singular no uso das tecnologias da informação nas regiões. Com o movimento mundial da Web 2.0 os governos com o intuito de se aproximar do cidadão e tornar suas ações mais transparentes estabelecem parâmetros e metas que o insere no mundo do e-government.

As iniciativas de reforma e modernização do setor público e do Estado intensificaram-se no final do século passado com o esgotamento do modelo de gestão burocrática e do modo de intervenção estatal (DINIZ et al., 2016). Nesse período inicia um movimento por reforma da gestão pública que buscava a excelência orientado para prestação de serviço ao cidadão. Esse movimento baseou-se em princípios gerenciais voltados a resultados, eficiência, governança e de gestão pública orientada para práticas de mercado.

Nessa perspectiva em se aproximar do cidadão e incluir no processo democrático (livre e aberto) o governo brasileiro implanta o Governo Digital do Brasil, o portal gov.br. Nessa ótica o governo federal busca atuar digitalmente frente ao cidadão, nesta relação Estado-Sociedade, vem, ao longo dos anos, inserindo-se nas discussões acadêmicas que têm proporcionado alterações nessa relação em termos de celeridade, conteúdo, transparência, eficiência/eficácia com crescimento de informação no portal e criando novas plataformas de interação. Atualmente o portal chama-se governo digital e apresenta os seus princípios como sendo:

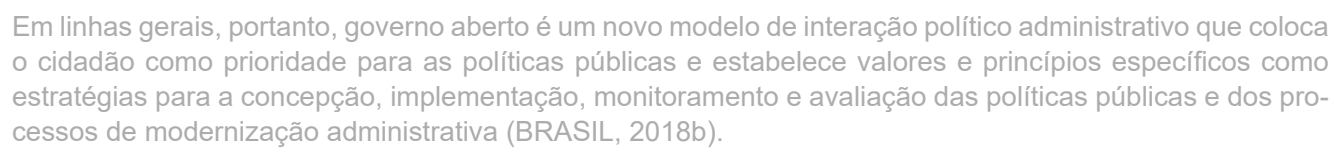

Como orientador para esse projeto foi criado um Grupo de Trabalho Interministerial com a finalidade de examinar e propor políticas, diretrizes e normas relacionadas às novas formas eletrônicas de interação, através do Decreto Presidencial de 3 de abril de 2000 (BRASIL, 2000).

Apesar das boas iniciativas identificadas, os diagnósticos realizados pelo Grupo de Trabalho em Tecnologia da Informação (doravante GTTI) criada pelo governo, identificaram a existência de uma infraestrutura deficitária, formada por uma malha de múltiplas e diversas redes administradas de forma isolada. Assim, os serviços não obedeciam a padrões de desempenho e interatividade, as interfaces com o usuário nem sempre eram amigáveis e se constatara um descompasso entre os diversos órgãos governamentais, no ritmo de assimilação das TICs haja em vista os sistemas corporativos da Administração Pública Federal (doravante APF) eram pouco integrados entre si e estavam estruturados com foco na gestão de funções e não de processos (BRASIL, 2018a).

Para resolver essas questões as ações deste GTTI foram formalizadas e incorporadas às metas do programa Sociedade da Informação, coordenado pelo Ministério da Ciência e Tecnologia em três linha de programa: (i)Universalização de serviços; (ii) Governo ao alcance de todos; (iii) Infraestrutura avançada (BRASIL, 2018a). Esse grupo de trabalho apresentou alguns relatórios que subsidiaram e impulsionaram o governo eletrônico.

O GTTI, por sua vez, apresentou o documento "Proposta de Política de Governo Eletrônico para o Poder Executivo Federal”. Logo em seguida, o Decreto de 18 de Outubro de 2000, criou o Comitê Executivo de Governo Eletrônico (CEGE), com o objetivo de formular políticas, estabelecer diretrizes, coordenar e articular as ações de implantação do Governo Eletrônico.

De entre as diretrizes o Brasil passa a participar como co-fundador do Open Government Partnership (OGP) que está fortemente comprometido em fortalecer a transparência das ações do governo, prevenir e combater a corrupção, fomentar os ideais democráticos com a participação do cidadão na tomada de decisões e na melhoria dos serviços públicos. Para isso desenvolveu várias iniciativas para melhorar sua estrutura legal, promover a participação dos cidadãos e usar a tecnologia para uma maior abertura. Para atender esses objetivos assumiu trinta e dois compromissos.

Esses compromissos, entretanto, produziram muitos benefícios importantes, como a criação do Portal de Dados Abertos, a organização da Conferência Nacional sobre transparência (CONSOCIAL) - que envolveu mais de 100 mil cidadãos - e a implementação da Lei Brasileira de Acesso à Informação. Mais de $90 \%$ dos compromissos firmados foram total ou parcialmente implementados e o país também adicionou outras onze iniciativas de governo aberto que não fazia, originalmente, parte do Plano de Ação (BRASIL, 2018a). 
Assim sendo, alguns especialistas como Araújo e Aguiar (2014) destacam iniciativas relacionadas à definição de padrões, a normatização, a articulação da integração de serviços eletrônicos, a disponibilização de boas práticas de TICs, permitiu a criação de infraestruturas, a implementação de práticas de gestão do conhecimento, dentre outras iniciativas, com a intenção de viabilizar a transformação social, inserindo o país cada vez mais na sociedade da informação, algumas de relevante destaque como a que se segue:

\begin{abstract}
Muitas realizações aconteceram para implementação dessas diretrizes e diversas iniciativas apresentaram resultados significativos, servindo de base para outras implantadas ou em desenvolvimento. Como exemplos dessas iniciativas pode-se mencionar: à criação do Portal ComprasNet, com informações sobre fornecedores, pregões eletrônicos e licitações públicas; o Portal da Transparência, que disponibiliza dados da execução orçamentária federal; o Portal de Convênios e Contratos de Repasse (SICONV); o Portal Brasil, com informações de diversas naturezas sobre o país; os Padrões de Interoperabilidade de governo eletrônico; os Padrões Web em Governo Eletrônico; o Modelo de acessibilidade de Governo Eletrônico (eMAG); o envio de declarações de imposto de renda pela internet; as eleições eletrônicas; o Guia de Serviços Públicos do Governo Federal - ambiente que agrupa mais de 500 serviços públicos; dentre outras. (ARAÚJO; AGUIAR, 2014 p.3)
\end{abstract}

Nesse pacote de outras iniciativas avanços ocorreram também na melhoria da gestão administrativa do Governo Federal com a sistematização e replicação de boas práticas, acompanhadas de um série de legislação que determina aos órgãos federais a disponibilizar seus dados dentre eles as universidades federais que precisam construir seus planos de Dados Abertos e inserir no Portal de Dados Abertos todas as informações de natureza académica e administrativa que a instituição produz.

Nesta perspectiva este paper visa identificar quais universidades federais estão respondendo a esta política. Apresentar um quadro de como as 68 universidades federais brasileiras estão se organizando para atender a demanda governamental, quantas já estão com dados abertos no portal nacional, e, quais critérios estão seguindo para construção de seus Planos de Dados Abertos na evolução para Ciência Aberta outro braço da transparência pública que está comprometido com OGP para a divulgação de dados das pesquisas desenvolvidas nas instituições de pesquisa no Brasil.

Finalmente há que salientar, o que o aporte científico e a metodologia de investigação que assentaram na pesquisa bibliográfica de artigos e livros de referência que tratam das questões atinentes à Ciência aberta e aos dados abertos governamentais, bem como às recentes perspectivas apontadas para a Ciência Aberta. Do mesmo modo, o Portal Dados.gov.br foi a principal fonte para busca documental para identificar quais universidades federais brasileiras estavam com seus dados disponibilizados; foi utilizada as técnicas de análise documental para estudo dos planos de dados abertos e o portal de dados para identificar que tipo de informações as universidades estão disponibilizando.

\title{
2 Revisão da literatura
}

A revisão da literatura foi subdividida em seções para melhor compreensão dos dados governamentais abertos, política(s) de Dados Abertos da Administração Pública Brasileira, portal dados.gov.br, Ciência Aberta e a ascensão do "papel de dados" e repositórios de dados, no sentido de dar resposta à questão: onde guardar conjuntos de dados?

\subsection{Dados governamentais abertos}

Quando se fala em Dados Abertos uma série de outros termos são mencionados como que derivando do termo norteador "Acesso Aberto" / "Open Access", cuja definição foi concretizada, posteriormente no Movimento de Livre Acesso ao Conhecimento Científico que teve como arranque decisivo a Declaração de Budapeste (Budapest Open Access Initiative/BOAI), publicada em 2002, na qual foram propostos o conceito e as estratégias para o acesso aberto por intermédio da Via Dourada (publicação em revistas de Acesso Aberto) e da Via Verde (auto-arquivo/depósito em repositórios de Acesso Aberto), dando cumprimento aos propósitos da reunião ocorrida em 2001. Esta iniciativa trouxe consigo uma crescente reflexão, mormente nos meios académicos, sobre o papel da ciência e sua contribuição para a promoção do desenvolvimento de sociedades mais equitativas e sustentáveis. Os membros deste movimento, posteriormente aprofundado com a Declaração de Bethesda (Bethesda Statement on Open Access Publishing), produzida em 2003 e a Declaração de Berlim (Berlim Declaration on Open Access to Knowledge in Science \& Humanities, 2003), defendem a reprodutibilidade, apelam à transparência científica, elogiam a velocidade de circulação da informação e a reutilização de dados, considerando que estes são requisitos fundamentais para a aceleração do processo de qualificação do conhecimento científico (NIELSEN, 2011). 
Segundo a definição da Open Knowledge International, os "dados são abertos quando qualquer pessoa pode livremente usá-los, reutilizá-los e redistribuí-los, estando sujeito a, no máximo, a exigência de creditar a sua autoria e compartilhar pela mesma licença" (TCU, 2015, p. 5).

Outros preferem falar de "Ciência comum", i.e. "Llamamos ciencia común a una forma de producir conocimiento que debe poder hacerse entre todos. La condición entre todos es distinta del para todos que caracteriza a los bienes públicos.Modos de ciencia: pública,abierta y común", numa dimensão ético-política (LAFUENTE; ESTALELLA, p. 52).

No desdobrando para Governo Aberto, Eaves (2009, citado por BRASIL, 2019) define "Dados Abertos Governamentais", como publicação e a disseminação das informações do setor público na web, compartilhadas em formato bruto aberto, compreensíveis logicamente, de modo a permitir a sua reutilização em aplicações digitais desenvolvidas pela sociedade, promovendo o exercício da cidadania informada e consciente.

A Organização para Cooperação e Desenvolvimento Econômico (doravante OCDE), corrobora que para que se considere um Governo Aberto o princípio da transparência deve ser considerado primordial. Nesse âmbito OCDE identifica três princípios-chave: a) accountability: a necessidade de existência de mecanismos que possibilitem a identificação e responsabilização dos servidores públicos pelas suas ações; b) transparência: disponibilização de informações confiáveis, relevantes e tempestivas sobre as atividades do governo; c) participação social: o governo deve escutar os cidadãos e empresas, e considerar os seus anseios tanto no desenho quanto na implementação das políticas públicas (UBALDI, 2013; FIOCRUZ, 2019).

Destacadamente, a accountability se impõe, de acordo com Da Silva Júnior (2008), devido ser um processo fundamental para a governança e governabilidade, pois envolve atores sociais nas diversas fases da gestão pública e implica assumir responsabilidades na condução do processo de análise e atendimento das demandas sociais. A Parceria para Governo Aberto, (https://www.opengovpartnership.org/about/about-ogp) que é uma iniciativa internacional criada em setembro de 2011, tem o Brasil, como cofundador, está focado no objetivo de difundir e incentivar globalmente práticas governamentais relacionadas à transparência dos governos, ao acesso à informação pública e à participação social, conforme informa a OGP Brasil home (2019).

O Brasil como membro ativo da OGP, reúne e fornece à sua população dados sobre suas ações, despesas, investimentos e projeções desde 2009, quando foi concebido o catálogo central de atividades públicas, para promover e supervisionar a atividade governamental (BREITMAN et al., 2012).

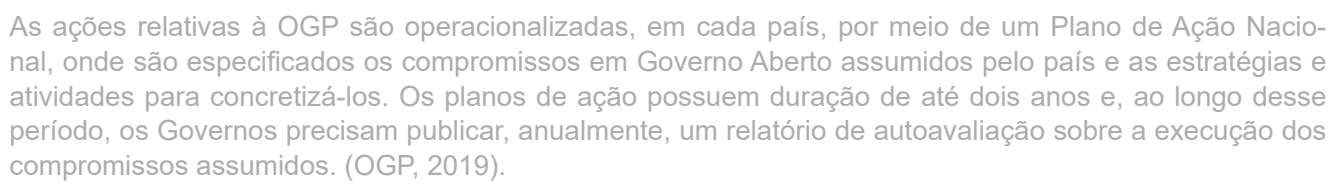

O Brasil lançou no final do ano de 2018 o quarto Plano de Ação do compromisso do Governo Aberto, especificamente, o Compromisso 3: Inovação e Governo Aberto na Ciência que estabelece mecanismos de governança de dados científicos para o avanço da Ciência Aberta no Brasil. Este trabalho logrou esforços para encontrar nos Planos de Dados Abertos das Universidades alguma informação que atenda esse compromisso. Para efeito de acompanhamento a execução de cada compromisso é monitorada pela Controladoria Geral da União (CGU) continuamente, órgão responsável pelo controle interno do Governo Federal, em conjunto com o Ministério do Planejamento, Orçamento e Gestão - MPOG, estabeleceram a Portaria Interministerial CGU/MPOG n. 140, de 16 de março de 2006, que determina que os órgãos e entidades da Administração Pública Federal são responsáveis por manter nos seus respectivos sítios eletrônicos as informações detalhadas de suas atividades.

Atualmente, a publicação de dados abertos é valorizada mundialmente em diversos campos de atuação (governamental, social e acadêmico) por promover maior transparência, eficiência e efetividade de serviços, além de possibilitar a inovação e a mensuração de impacto de políticas públicas. Porém, este recurso ainda é pouco explorado por muitos países. (FIOCRUZ, 2019).

As instituições acadêmicas têm como compromisso avançar nos processos relacionados à disponibilização de dados abertos de pesquisa científica por meio do aprimoramento de instrumentos de governança. Respaldando a Agenda 2030: 9.5 que tem por objetivo "fortalecer a pesquisa científica, melhorar as capacidades tecnológicas de setores industriais em todos os países" (ONU, s,d).

Segundo Albagli, Clinio e Raychtock (2014), a expressão "dados abertos" tem sido usualmente utilizada para fazer referência à transparência de dados governamentais, mas, na verdade, o termo é mais amplo e abrange pelo menos 8 categorias de dados que são: 
Cultural, científica, financeira, estatística, climática, ambiental, viária e geográfica. No campo científico, trata-se da publicitação de dados primários de uma pesquisa, considerada uma ação fundamental para sua reprodutibilidade e reutilização em pesquisas derivadas ou não, além de permitir o amplo escrutínio, o que pode contribuir para expor inconsistências, baixa qualidade, plágio ou fraude. (grifo nosso).

Um evento ocorrido em 2007 nos EUA organizado por um grupo de defensores de dados abertos, denominado Open Government Working Group propôs um conjunto de oito princípios fundamentais para os dados abertos governamentais, a saber:

\begin{abstract}
Completos: todos os dados públicos estão disponíveis. Entende-se por dado público o dado que não está sujeito a limitações válidas de privacidade, segurança ou controle de acesso. Primários: os dados são apresentados tais como os coletados na fonte, com o maior nível de granularidade e sem agregação ou modificação. Atuais: os dados são disponibilizados tão rapidamente quanto necessária à preservação do seu valor. Acessíveis: os dados são disponibilizados para o maior alcance possível de usuários e para o maior conjunto possível de finalidades. Compreensíveis por máquinas: os dados são razoavelmente estruturados de modo a possibilitar processamento automatizado. Não discriminatórios: os dados são disponíveis para todos, sem exigência de requerimento ou cadastro. Não proprietários: os dados são disponíveis em formato sobre o qual nenhuma entidade detenha controle exclusivo; e Livres de licenças: os dados não estão sujeitos a nenhuma restrição de direito autoral, patente, propriedade intelectual ou segredo industrial. As restrições sensatas relacionadas à privacidade, segurança e privilégios de acesso devem ser permitidas. (TCU, 2015 apud VICTORINO et al, 2017).
\end{abstract}

Os dados abertos governamentais e administrativos dizem respeito a assuntos diversos e podem envolver desde dados sobre despesas e receitas do governo até dados sobre censo escolar, pontos turísticos, reclamações de consumidores, demandas de serviços, entre outros.

Neste estudo foram considerados apenas os dados abertos governamentais administrativos das Universidades Federais disponíveis no portal dados.gov.br.

\title{
2.2 Política(s) de dados abertos da administração pública brasileira
}

Para atender as prerrogativas de Dados Abertos Governamentais o Brasil lançou o Portal Brasileiro de Dados Abertos em 2012, liderado pelo Ministério do Planejamento. A iniciativa de abertura dos dados por parte dos governos foi impulsionada pela procura de transparência, de colaboração e de participação da sociedade/comunidade (GOLDSTEIN; DYSON, 2013).

A Infraestrutura Nacional de Dados Abertos (doravante INDA) é um conjunto de padrões, tecnologias, procedimentos e mecanismos de controle criados no Brasil para atender às condições de disseminação e compartilhamento de dados e informações públicas no modelo de Dados Abertos, em conformidade com o disposto na e-PING. O componente fundamental da INDA é o Portal Brasileiro de Dados Abertos, ele tem como objetivo ser o ponto central para a busca, o acesso e uso dos dados abertos governamentais no Brasil.

O Plano de Ação é o instrumento de planejamento para alcançar os objetivos da INDA em direção à sua visão institucional brasileira. O plano é previsto no inciso VII do art. $6^{\circ}$ da Instrução Normativa SLTI/MP n $4 / 2012$. Esse Plano compreende ações centrais, no nível da política de dados abertos como um todo. Contém as iniciativas específicas para cada organização pública e como ela deverá implementar através do instrumento denominado Plano de Dados Abertos, o qual deverá ser elaborado e implementado diretamente pela própria instituição, seguindo o processo definido no "kit para Dados Abertos".

Os princípios e objetivos estratégicos da Estratégia de Governança Digital (EGD) estão focados em pautar a elaboração tanto do Plano de Ação da INDA quanto dos Planos de Dados Abertos. Em relação à EGD, destacam-se os seguintes objetivos estratégicos: (i) fomentar a disponibilização e o uso de dados abertos; (ii) ampliar o uso de TIC para promover a transparência e dar publicidade à aplicação dos recursos públicos Pode-se afirmar que a promoção para a informação está voltada para orientar corretamente todos os órgão para isso o portal disponibiliza os seguintes documentos de orientação:

a) Cartilha Técnica para Publicação de Dados Abertos no Brasil

A Cartilha é um instrumento que estabelece as diretrizes táticas para a implementação da política de dados abertos no governo federal e também uma possível referência para as demais instâncias brasileiras harmonizarem as suas implementações de dados abertos. Ela baseou-se no documento Propuesta de Norma Técnica para Publicación de Datos do governo do Chile em janeiro de 2012. Dentre o seu conteúdo, destacam-se a exemplificação de formatos abertos e de processos de publicação, a definição do padrão de metadados da INDA, a possibilidade estruturação de catálogos de dados abertos setoriais por órgão e a 


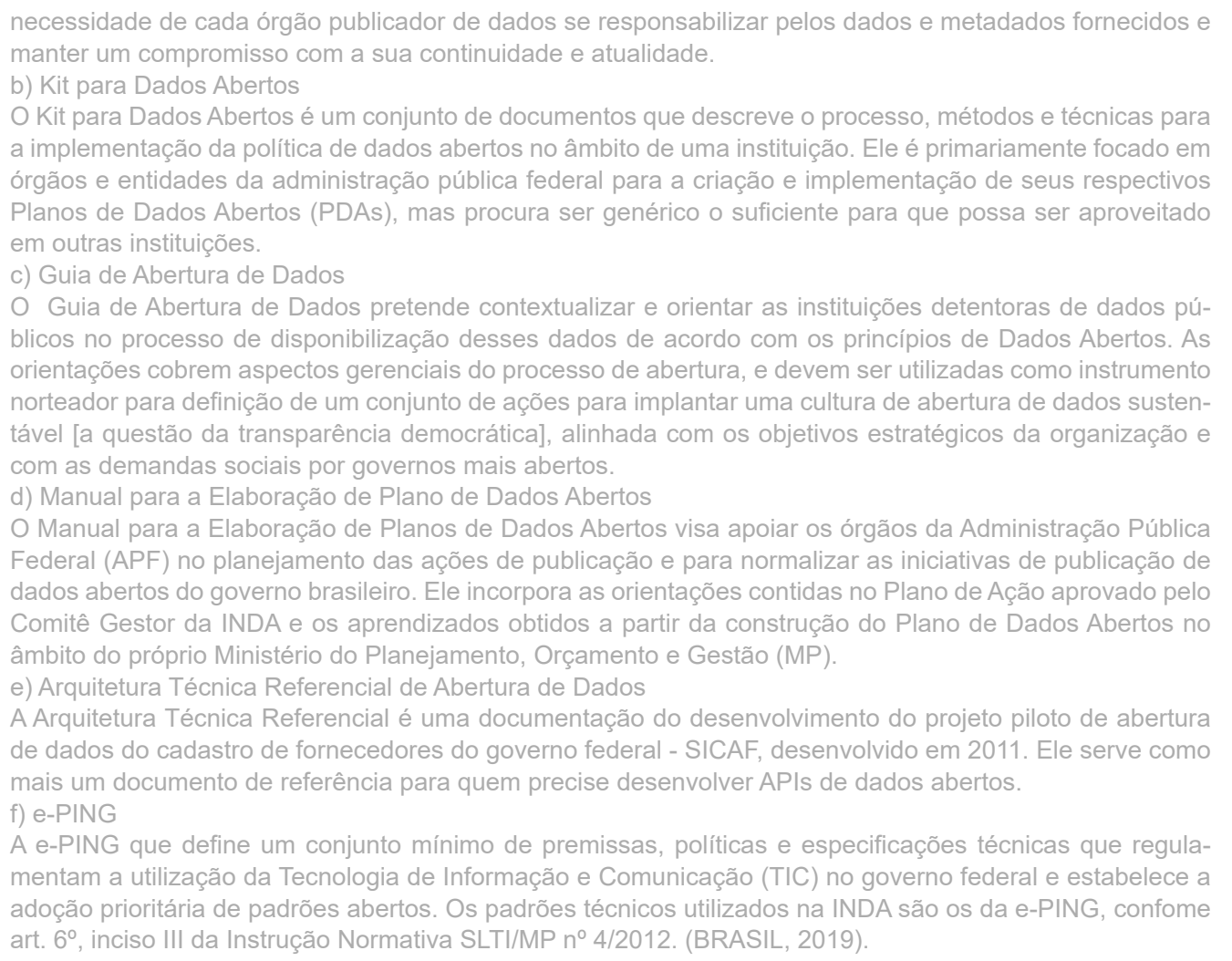

Vieira e Álvaro (2018) fizeram um estudo nos portais brasileiros de transparência para identificar a necessidade de implementar uma tecnologia física ou infraestrutura de hardware e propor o desenvolvimento de uma plataforma de coleta, processamento e armazenamento de OGD como fonte de dados disponibilizados nos banco de dados do Governo Aberto e nos demais bancos de dados de outros órgão como Câmara dos Deputados, do Senado Federal e portais associados a cidades e prefeituras. Esse estudo está voltado para a agregação dos dados por software que com certeza é um passo à frente que os dados abertos terão que fazer futuramente.

\subsection{Portal dados.gov.br}

O portal dados.gov.br, na prática, considera que a filosofia de dados abertos estipula algumas questões tecnológicas para que os dados sejam legíveis por máquina, considerando que "todo dado público tem vocação para ser dado aberto. Como praticamente todo dado governamental é público, é fundamental que os governos implementem políticas para disponibilizá-los." O portal dados.gov.br tem o objetivo de ser o ponto único referencial para a busca e o acesso à dados públicos brasileiros de todo e qualquer assunto ou categoria. Ele é um serviço simplificado que organiza e padroniza o acesso aos dados públicos, primando pelo reúso dos dados e o uso de tecnologias modernas. (BRASIL, 2019).

Os portais brasileiros de transparência sofrem com a falta de padronização e utilização dos formatos exigidos pela publicação o banco de dados do Governo Aberto que não estão associados aos demais bancos de dados de outros órgão como Câmara dos Deputados, do Senado Federal e portais associados a cidades e prefeituras que disponibilizam dados abertos da mesma forma são descentralizados os portais de fornecimento de dados governamentais já apontados também por Vieira e Álvaro (2018).

A perspectiva é que se crie valor econômico e social através dos dados abertos do governo, há evidências cada vez mais sólidas que dados dos muitos governos nacional e locais estãos sendo utilizados para fins econômicos. No entanto, a criação de valor potencial também são esperados na áreas políticas e sociais a partir das informações disponibilizadas em acesso aberto.

Para este trabalho o portal dados.gov.br foi mapeado nos meses de janeiro a abril de dois mil e dezenove, e, foi identificado cento e quarenta e uma (141) organizações que já possuem dados disponíveis no portal, a saber: são eles os órgãos, as autarquias, ou entidades da Administração Pública que disponibilizam dados em formato aberto. No início da pesquisa em janeiro 2019 eram 138 agora no final de abril já são 141. Deste total vinte e nove (29) são Universidades Federais de Ensino Superior foco deste estudo. 
Dados abertos e ciência aberta: como as universidades federais brasileiras se apresentam nesse horizonte

\subsection{Ciência aberta e a ascensão do "papel de dados"}

Ciência Aberta é a atividade científica praticada de modo aberto, colaborativo e transparente, em todos os domínios do conhecimento, em todas as esferas sociais e das humanidades. A Ciência Aberta é considerada mais do que o acesso aberto às publicações e dados de pesquisa, ela vai além da abertura dos resultados da pesquisa, sua prática implica que o processo de pesquisa seja ele próprio aberto, usando métodos, ferramentas e workflows que facilitem a partilha, reutilização e colaboração. Por isso, a Ciência Aberta é um conceito abrangente que se baseia em diversos pilares e inclui múltiplas dimensões. (FIOCRUZ, 2019).

A Ciência Aberta apresenta algumas vantagens que fortalecem os envolvidos nas atividades da ciência, como aponta FIOCRUZ (2019):

\footnotetext{
Ciência Aberta corresponde às melhores práticas científicas e promove a qualidade e a eficiência da pesquisa e da ciência. Nesse sentido, alguns dizem que a Ciência Aberta é apenas a "boa ciência", ou a ciência realizada do modo certo. Mas, para além disto, a prática da Ciência Aberta tem revelado inúmeras vantagens para os pesquisadores, para as instituições de pesquisa, para as agências de fomento e outros financiadores de pesquisa, bem como para a sociedade em geral.

A partilha dos resultados e dos métodos de pesquisa potencia o seu conhecimento e reutilização por outros. A sua pesquisa será mais visível, poderá ter maior impacto e isso facilitará o estabelecimento de novas parcerias e colaborações.

Usando as práticas da ciência aberta, todo o processo de pesquisa, e a geração de novos conhecimentos, podem ser acelerados e tornados mais eficientes. Isso significa que o retorno do investimento na pesquisa é maximizado, contribuindo para o crescimento económico e o bem estar das sociedades, e para encontrar soluções para os desafios ambientais e sociais que enfrentamos.
}

Dessa forma algumas razões são apontadas para incentivar a Ciência Aberta: Preserva, valoriza e partilha a produção científica; Promove o Acesso Aberto / FAIR (Findable, Accessible, Interoperable, and Re-usable) aos dados e publicações científicas; Protege e valoriza a propriedade intelectual; Promove a eficiência do processo científico; Aumenta a visibilidade e reconhecimento dos investigadores e das instituições; Amplifica o impacto da investigação, estimula a criatividade e a inovação; Promove a responsabilidade social científica e a apropriação social do conhecimento; Promove a transparência e o conhecimento do processo científico; Envolve a sociedade no processo de (co) criação e fruição do conhecimento; Democratiza o acesso ao conhecimento. (FIOCRUZ, 2019 adaptado de CC-BY)

As autoras Albagli, Clinio e Raychtock (2014) apontam que as ações em ciência aberta são vistas com entusiasmo por uma parcela dos cientistas, mas encontram também muita resistência por outra parte, não apenas pela dificuldade de aprender a lidar com essas novas práticas (e a necessidade de absorver novas tarefas e habilidades), mas também pelos deslocamentos de poder que tais mudanças frequentemente envolvem.

Essas razões devem ser norteadoras para a abertura da ciência nas universidades federais que são fontes geradoras e incentivadoras da produção científica.

A corrente open access ascendeu a novo horizonte para além de dados administrativos governamentais surgiu a necessidade de chegar à "Ciência Aberta" recorrendo a grandes centros de pesquisa orientar sobre o que são e como guardar conjuntos de dados, por exemplo, a Oregon State University, em sua plataforma destaca que "os conjuntos de dados estão sendo cada vez mais reconhecidos como produtos acadêmicos por si mesmos e, como tal, estão sendo submetidos agora para publicação independente" e que o valor desses conjuntos de dados estão em ascensão que seu valor consiste em compartilhar informação, como destaca:

\footnotetext{
Em muitos casos, o maior valor de um conjunto de dados consiste em compartilhá-lo, não necessariamente em fornecer interpretação ou análise. Esse conjunto de dados de referência, que continuará a evoluir com o tempo, é um valioso produto de pesquisa autônomo que possui valor intrínseco. Nos modelos tradicionais de publicação, esse conjunto de dados não seria considerado "publicável" porque não apresenta novas pesquisas ou interpretações de resultados. Os documentos de dados facilitam o compartilhamento de dados em uma estrutura padronizada que fornece valor, impacto e reconhecimento para os autores. Os documentos de dados também fornecem um contexto e uma descrição muito mais completos do que os conjuntos de dados que são simplesmente depositados em um repositório, que pode ter requisitos mínimos de metadados. (OREGON STATY UNIVERSITY, 2019 tradução livre).
}

Estes dados assumem um papel que diferem das publicações tradicionais uma vez que "descrevem completamente os conjuntos de dados e geralmente não incluem nenhuma interpretação ou discussão, uma exceção pode ser a discussão de diferentes métodos para coletar os dados, por exemplo". Esses documentos de dados são publicados em seção distinta em periódico bem específicos que se concentram exclusivamente na publicação de conjuntos de dados e que oferecem acesso rápido a conjuntos de dados de alta qualidade de amplo interesse para a comunidade científica "facilitando a sua reutilização que aumenta seu valor e impacto originais e acelera 
o ritmo da pesquisa, evitando a duplicação não intencional de esforços". (OREGON STATY UNIVERSITY, 2019, tradução livre).

\subsection{Repositórios de dados: onde guardar conjuntos de dados?}

Segundo a Oregon (2019), a preservação de dados é questão decorrente dos documentos / conjuntos de dados mais ou menos organizados de dados, que não o seu objetivo principal. A maioria dos periódicos de dados não arquiva dados internamente, para esse objetivo existem vários repositórios para atender à procura em que os dados são arquivados e são atribuídos identificadores persistentes e exclusivos para esse fim.

Para exemplificar citamos alguns repositórios de dados. Esses repositórios arquivam os dados, fornecem acesso persistente e atribuem ao conjunto de dados um identificador exclusivo (DOI). Os repositórios nem sempre exigem que o (s) conjunto (s) de dados sejam vinculados a uma publicação (papel de dados ou papel 'típico'; o Dryad requer um):

Quadro 1 - Alguns Repositório de dados

\begin{tabular}{|c|c|c|c|}
\hline $\begin{array}{c}\text { Repositórios de } \\
\text { Dados }\end{array}$ & Filiação & Prerrogativas & Recomendações \\
\hline $\begin{array}{l}\text { PANGEA } \\
\text { https://www.pan- } \\
\text { gaea.de }\end{array}$ & $\begin{array}{l}\text { O World Data Center } \\
\text { PANGEA é membro do } \\
\text { ICSU World Data System. } \\
\text { O sistema de informação } \\
\text { PANGEA é operado como } \\
\text { uma biblioteca de Acesso } \\
\text { Aberto destinada a arqui- } \\
\text { var, publicar e distribuir } \\
\text { dados georreferenciados } \\
\text { da pesquisa do siste- } \\
\text { ma terrestre. O sistema } \\
\text { garante a disponibilidade } \\
\text { de longo prazo de seu } \\
\text { conteúdo através de um } \\
\text { compromisso das insti- } \\
\text { tuições de hospedagem. }\end{array}$ & $\begin{array}{l}\text { A maioria dos dados está } \\
\text { disponível gratuitamente e } \\
\text { pode ser usada sob os ter- } \\
\text { mos da licença mencionada } \\
\text { na descrição do conjunto de } \\
\text { dados. Alguns conjuntos de } \\
\text { dados protegidos por senha } \\
\text { estão sob moratória de } \\
\text { projetos em andamento. A } \\
\text { descrição de cada conjunto } \\
\text { de dados é sempre visí- } \\
\text { vel e inclui o investigador } \\
\text { principal (PI) que pode ser } \\
\text { solicitado para acesso }\end{array}$ & $\begin{array}{l}\text { O arquivamento segue as } \\
\text { Diretrizes da Comissão Eu- } \\
\text { ropeia sobre Acesso Aberto } \\
\text { a Publicações Científicas } \\
\text { e Dados de Pesquisa no } \\
\text { Horizonte } 2020 \text { e as reco- } \\
\text { mendações da DFG para } \\
\text { salvaguardar boas práticas } \\
\text { científicas. O PANGEA está } \\
\text { ainda mais alinhado com os } \\
\text { Princípios e Diretrizes da } \\
\text { OCDE para o Acesso a Da- } \\
\text { dos de Pesquisa do Fundo } \\
\text { Público, bem como com os } \\
\text { Princípios Orientadores do } \\
\text { FAIR para gerenciamento de } \\
\text { dados científicos e adminis- } \\
\text { tração. }\end{array}$ \\
\hline $\begin{array}{l}\text { ScholarsArchive @ } \\
\text { OSU } \\
\text { https://ir.library. } \\
\text { oregonstate.edu/ }\end{array}$ & $\begin{array}{l}\text { Consórcio interuniversi- } \\
\text { tário de pesquisa política } \\
\text { e social (ICPSR) - O } \\
\text { maior arquivo do mundo } \\
\text { de dados de ciências } \\
\text { sociais digitais. ICPSR } \\
\text { orienta na preparação de } \\
\text { dados para arquivamento } \\
\text { e distribuição. } \\
\text { Repositório criado para } \\
\text { capturar, distribuir e } \\
\text { preservar os produtos } \\
\text { digitais dos professores e } \\
\text { alunos da OSU. Scholars } \\
\text { Archive @ OSU é uma } \\
\text { opção para disponibilizar } \\
\text { seus dados publicamen- } \\
\text { te e garantir acesso de } \\
\text { longo prazo a eles, de- } \\
\text { pendendo da natureza do } \\
\text { conteúdo e do tamanho } \\
\text { dos conjuntos de dados. } \\
\text { Disponibiliza as Diretrizes } \\
\text { para Contribuições do } \\
\text { Conjunto de Dados de } \\
\text { Pesquisa no ScholarsAr- } \\
\text { chive @ OSU }\end{array}$ & $\begin{array}{l}\text { Armazena, organiza e } \\
\text { fornece acesso a dados } \\
\text { científicos para que outros } \\
\text { possam reutilizar os dados } \\
\text { e validar os resultados da } \\
\text { pesquisa. I }\end{array}$ & $\begin{array}{l}\text { A curadoria, do latim "to } \\
\text { care", é o processo que o } \\
\text { ICPSR usa para agregar } \\
\text { valor aos dados, maximi- } \\
\text { zar o acesso e garantir a } \\
\text { preservação a longo prazo. } \\
\text { https://www.icpsr.umich.edu/ } \\
\text { icpsrweb/content/datamana- } \\
\text { gement/index.htm }\end{array}$ \\
\hline
\end{tabular}




\begin{tabular}{|c|c|c|c|}
\hline $\begin{array}{l}\text { Dryad } \\
\text { http://datadryad.org/ }\end{array}$ & $\begin{array}{l}\text { Repositório disciplinar } \\
\text { internacional de dados } \\
\text { subjacentes a publi- } \\
\text { cações científicas e } \\
\text { médicas. O Dryad é um } \\
\text { repositório de uso geral } \\
\text { com curadoria que torna } \\
\text { os dados detectáveis, } \\
\text { livremente reutilizáveis e } \\
\text { citáveis. (Wikipedia). } \\
\text { A Dryad é uma organi- } \\
\text { zação sem fins lucrativos } \\
\text { que fornece acesso de } \\
\text { longo prazo ao seu con- } \\
\text { teúdo sem nenhum custo } \\
\text { para pesquisadores, edu- } \\
\text { cadores ou estudantes, } \\
\text { independentemente da } \\
\text { nacionalidade ou afiliação } \\
\text { institucional. }\end{array}$ & $\begin{array}{l}\text { A Dryad é capaz de for- } \\
\text { necer acesso gratuito aos } \\
\text { dados devido ao suporte } \\
\text { financeiro dos membros e } \\
\text { dos responsáveis pelo en- } \\
\text { vio de dados. O DPC base } \\
\text { por pacote de dados é de } \\
\text { US } \$ 120 \text {. } \\
\text { cobra taxas de armaze- } \\
\text { namento em excesso por } \\
\text { pacotes de dados que } \\
\text { totalizam mais de } 20 \text { GB. } \\
\text { Essas taxas excedentes } \\
\text { são cobradas do remeten- } \\
\text { te, mesmo se houver um } \\
\text { patrocinador em vigor para } \\
\text { o DPC }\end{array}$ & $\begin{array}{l}\text { As renúncias são concedidas } \\
\text { mediante solicitação de en- } \\
\text { vios provenientes de pesqui- } \\
\text { sadores localizados em paí- } \\
\text { ses classificados pelo Banco } \\
\text { Mundial como economias de } \\
\text { baixa ou média baixa renda. } \\
\text { https://datadryad.org/ }\end{array}$ \\
\hline $\begin{array}{l}\text { re3data.org } \\
\text { https://www.re3data. } \\
\text { org/ }\end{array}$ & $\begin{array}{l}\text { Registro de Repositórios } \\
\text { de Dados de Pesquisa. O } \\
\text { re3data.org é um registro } \\
\text { global de repositórios de } \\
\text { dados de pesquisa que } \\
\text { abrange repositórios de } \\
\text { dados de pesquisa de } \\
\text { diferentes disciplinas } \\
\text { acadêmicas. Apresenta } \\
\text { repositórios para o ar- } \\
\text { mazenamento permanen- } \\
\text { te e acesso de conjuntos } \\
\text { de dados a pesquisado- } \\
\text { res, órgãos financiadores, } \\
\text { editores e instituições } \\
\text { acadêmicas. }\end{array}$ & $\begin{array}{l}\text { promove uma cultura de } \\
\text { compartilhamento, maior } \\
\text { acesso e melhor visibilidade } \\
\text { dos dados da pesquisa. O } \\
\text { registro foi lançado no ou- } \\
\text { tono de } 2012 \text { e é financiado } \\
\text { pela Fundação Alemã de } \\
\text { Pesquisa DFG. }\end{array}$ & $\begin{array}{l}\text { É recomendado nas " Dire- } \\
\text { trizes sobre o Acesso Aberto } \\
\text { a Publicações Científicas e } \\
\text { Dados de Pesquisa no Ho- } \\
\text { rizonte } 2020 \text { " da Comissão } \\
\text { Europeia }\end{array}$ \\
\hline $\begin{array}{l}\text { Simmons Colle- } \\
\text { ge Open Access } \\
\text { Directory } \\
\text { http://oad.simmons. } \\
\text { edu/oadwiki/Data } \\
\text { repositories }\end{array}$ & $\begin{array}{l}\text { um diretório de repositó- } \\
\text { rios de dados de acesso } \\
\text { aberto, por disciplina. } \\
\text { Open Access Directory } \\
\text { (OAD) é um compêndio } \\
\text { de listas factuais simples } \\
\text { sobre o acesso aberto } \\
\text { (OA) à ciência e à bolsa } \\
\text { de estudos, mantido pela } \\
\text { comunidade OA em geral. }\end{array}$ & $\begin{array}{l}\text { Sob uma licença Creative } \\
\text { Commons Attribution } 3.0 \\
\text { Unported. Qualquer pessoa } \\
\text { pode ler, copiar ou redis- } \\
\text { tribuir seu conteúdo sem } \\
\text { taxa, permissão ou registro, } \\
\text { desde que credite o OAD } \\
\text { como a fonte. } \\
\text { Os privilégios de edição no } \\
\text { OAD estão limitados aos } \\
\text { usuários registrados }\end{array}$ & $\begin{array}{l}\text { Reunindo muitas listas } \\
\text { relacionadas ao OA em um } \\
\text { único local, o OAD facilita } \\
\text { a descoberta por todos, as } \\
\text { utiliza como referência e } \\
\text { as atualiza. Quanto mais } \\
\text { fáceis de manter e descobrir, } \\
\text { mais eficazmente podem } \\
\text { divulgar informações úteis e } \\
\text { precisas sobre a AO. http:// } \\
\text { oad.simmons.edu/oadwiki/ } \\
\text { Main_Page }\end{array}$ \\
\hline
\end{tabular}

Fonte: Adaptado de Oregon (2019).

\section{Análise e discusão}

A análise dos dados encontrados a partir da pesquisa são descritos abaixo.

\subsection{Universidade com dados abertos}

A pesquisa apontou que de um universo de sessenta e oito (68) Universidades de Ensino Superior Públicas Brasileira, apenas vinte e nove (29) já estão com seus Planos de Dados Abertos disponíveis no Portal Dados. gov.br nele essas instituições estão disponibilizando seiscentos e noventa (690) conjuntos de dados produzidos pelas universidades divididos em 207 termos. Abaixo a lista das universidades por região e conjuntos de dados disponibilizados: 
Quadro 2 - Universidades com dados abertos por Região

\begin{tabular}{|c|c|c|}
\hline Região & Universidades & Conjunto de dados disponíveis \\
\hline \multirow[t]{6}{*}{ Sul } & Univ. da Fronteira do Sul & 69 \\
\hline & Univ. F. de Ciência da Saúde de Porto Alegre & 11 \\
\hline & Univ. F. de Santa Maria & 16 \\
\hline & Univ. Federal do Pampa & 02 \\
\hline & Univ. F. do Rio Grande do Sul & 03 \\
\hline & Univ. Fed. de Pelotas & 28 \\
\hline \multirow[t]{11}{*}{ Sudeste } & Univ. F. do Triângulo Mineiro & 16 \\
\hline & Univ. F. do Rio de Janeiro & 07 \\
\hline & Univ. Fed. do Espírito Santo & 05 \\
\hline & Univ. Fed. de Viçosa & 14 \\
\hline & Univ. Fed. de São João Del-Rei & 11 \\
\hline & Univ. Fed. de Lavras & 7 \\
\hline & Univ. Fed. de Juiz de Fora & 07 \\
\hline & Univ. Fed. de Itajubá & 07 \\
\hline & Univ. Fed. de Alfenas & 05 \\
\hline & Univ. Fed. do Vale do Jequitinhonha e Mucuri & 13 \\
\hline & Univ. Fed. de Ouro Preto & 74 \\
\hline \multirow[t]{2}{*}{ Norte } & Univ. Fed. de Roraima & 62 \\
\hline & Univ. Fed. do Sul e Sudeste do Pará & 30 \\
\hline \multirow[t]{9}{*}{ Nordeste } & Univ. Fed. Rural do Semi-Árido & 10 \\
\hline & Univ. Fed. do Vale de São Francisco & 30 \\
\hline & Univ. Fed. do Rio Grande do Norte & 71 \\
\hline & Univ. Fed. do Piauí & 25 \\
\hline & Univ. Fed. do Oeste da Bahia & 34 \\
\hline & Univ. Fed. do Maranhão & 20 \\
\hline & Univ. Fed. do Cariri & 43 \\
\hline & Univ. Fed. da Lusofonia Afro-Brasileira & 50 \\
\hline & Univ. Fed. do Recôncavo da Bahia & 5 \\
\hline Centro-oeste & Univ. Fed. do Mato Grosso do Sul & 15 \\
\hline
\end{tabular}

Fonte: Dados da pesquisa adaptado de Dados.gov.br (2019)

Destaca-se a Região Sudeste com mais instituições, são 11 (onze) Universidades que já atendem a política de dados abertos, no entanto, o conjunto de dados disponibilizados ainda é muito incipiente representados por 166 (cento e sessenta e seis) conjunto de dados; a região está em desvantagem em relação Região Nordeste que tem 9 (nove) universidades registradas e com 288 (duzentos e oitenta e oito) conjuntos de dados registrados, seguidos da Região sul com 6 (seis) universidades apresentando 129 (cento e vinte e nove) conjuntos de dados; a Região Norte com 2 (duas) universidades disponibiliza 92 (noventa e dois) conjuntos de dados e por último a Região Centro Oeste com apenas 01 (uma) universidade e 15 (quinze) conjuntos de dados, conforme pode ser observado no Gráfico 1 abaixo: 
Gráfico 1- Distribuição das universidades com dados abertos por região do Brasil

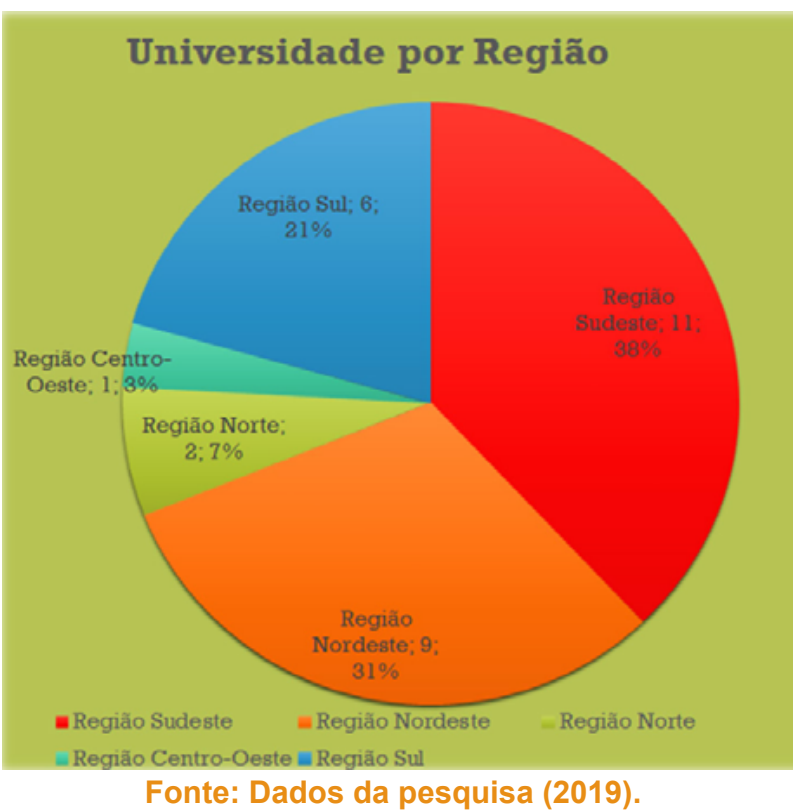

Ao se observar os conjuntos de dados percebe-se que nem todos seguem os mesmo padrão, algumas instituições subdividem um conjunto, por exemplo lista dos beneficiários de auxílio permanência, ao invés de abrir uma pasta com esse título e dentro dela outras com os anos disponíveis, abrem uma pasta para cada ano, dando a impressão que têm mais conjuntos de dados, quando na verdade ele pode ser agrupado a uma só.

Os termos utilizados também nem sempre são padronizados tem variações de nome de um dado de uma instituição para outra instituição para entrada de um mesmo conjunto de informação. Exemplos de conjuntos de informação com nomes diferentes mas que representam o mesmo tipo de informação "Beneficiários do PNAES" e "Assistência Estudantil"; "Auxílio estudantil por nacionalidade/porcentagem" e "Auxílio estudantil por Curso"; "Cursos de Pós-graduação" e "Programa de pós-graduação"; "Informações Acadêmicas - aluno do curso graduação" e "Informações de ingressante - curso de graduação"; "Relação Unidade Acadêmica" e "Relação Unidade Acadêmica Administrativa"; "informações administrativas" e "funções gratificadas".

Dentre os conjuntos de dados apresentados identificamos na planilha alguns que se repetem por algumas Universidades os quais destacamos no quadro abaixo:

Quadro 3 - Conteúdo/Termos mais utilizados pelas Universidades

\begin{tabular}{|c|c|}
\hline Termos utilizados & Uniersidade que utilizam \\
\hline $\begin{array}{l}\text { Acervo bibliográfico; Aluno de graduação; Concur- } \\
\text { so; Estrutura curricular; Editais; Empenho; Estoque; } \\
\text { Requisição de materiais; Lista telefônica; Matriz } \\
\text { curricular; Processo seletivo; Indicadores sociais dos } \\
\text { ingressantes; Informação acadêmica }\end{array}$ & UNIFESSPA; UFRJ; UNIPAMPA \\
\hline $\begin{array}{l}\text { Matriculados; Execução orçamentária; Servidores } \\
\text { técnicos administrativo; Servidores administrativos ati- } \\
\text { vos; Servidores administrativos pensionistas; Quanti- } \\
\text { tativos alunos de graduação; Plano de dados Abertos; } \\
\text { Relação de docentes; Relação de pesquisadores; } \\
\text { Solicitações na ouvidoria }\end{array}$ & UFOB; UFCA; UNIFESSPA; UFRR \\
\hline $\begin{array}{l}\text { Benefíciários do PNAES; Currículo; Diárias e passa- } \\
\text { gens; Unidades acadêmicas; Licitações; }\end{array}$ & UFOB; UFRR; UNIVASF; UNIFESSPA; UFRJ \\
\hline $\begin{array}{l}\text { Atividades de extensão; Projetos de extensão; Tur- } \\
\text { mas por semestres; Convênios; Grupos de pesquisa; } \\
\text { Convênios; Processos administrativos }\end{array}$ & UFOP; UFCSPA; UFV; UNIFESSPA; UFERSA \\
\hline
\end{tabular}




\begin{tabular}{|l|c|}
\hline $\begin{array}{l}\text { Informação docentes; Quantitativos alunos de } \\
\text { pós-graduação }\end{array}$ & $\begin{array}{c}\text { UFRR; UNILAB; UFES UFMA; UFRJ; UNIFESSPA; } \\
\text { UFTM }\end{array}$ \\
\hline Contratos; Funções gratificadas & $\begin{array}{c}\text { UFOP; UFRR;UFMS; UFPEL; UFCA; UFSJ; UFRJ; } \\
\text { UNIFESSPA }\end{array}$ \\
\hline $\begin{array}{l}\text { Cursos e programas de pós-graduação; Informação } \\
\text { acadêmica dos ingressantes; Categorias de servido- } \\
\text { res; (10) }\end{array}$ & $\begin{array}{c}\text { UFMS; UNIFEI; UNILAB; UFFS; UFSJ; UFCA; UFMA; } \\
\text { UFPI; UFRJ; UFERSA }\end{array}$ \\
\hline $\begin{array}{l}\text { Programa tutorial- PET; Projetos de pesquisa (11) } \\
\text { Curso de graduação (15) }\end{array}$ & $\begin{array}{c}\text { UFCSPA; UFOP; UFLA UFV;UFOB; UFRJ; UNI- } \\
\text { FESSPA; UFTM;UFERSA }\end{array}$ \\
\hline & $\begin{array}{c}\text { UFMS; UFEI; UNILAB; UNIFAL_MG UFFS; UFSJ; } \\
\text { UFCA; UFV; UFMA; UFOB; UFPI; UFRJ; UNIFESS- } \\
\text { PA; UFTM; UFERSA }\end{array}$ \\
\hline
\end{tabular}

Fonte: Dados da pesquisa adaptado de Dados.gov.br (2019)

Dentre os termos mais utilizados está o conjunto de dados relacionados a Graduação, utilizado por quinze (15) universidades, seguidos de projetos de pesquisas e programa tutorial (PET) que onze (11) universidade disponibilizam esses dados. Como já registrado acima há uma falta de padronização nos termos o que faz com que muitos termos sejam citados apenas por uma universidade, ou seja a maioria dos duzentos e sete termos são conjuntos de uma única universidade.

No Gráfico 2, abaixo, destacamos o número de dados disponíveis por cada Região a Região Nordeste a segunda colocada em quantidade de Universidade com dados já disponibilizados é a que mais tem dados abertos.

Gráfico 2- Distribuição das universidades com dados abertos por região do Brasil

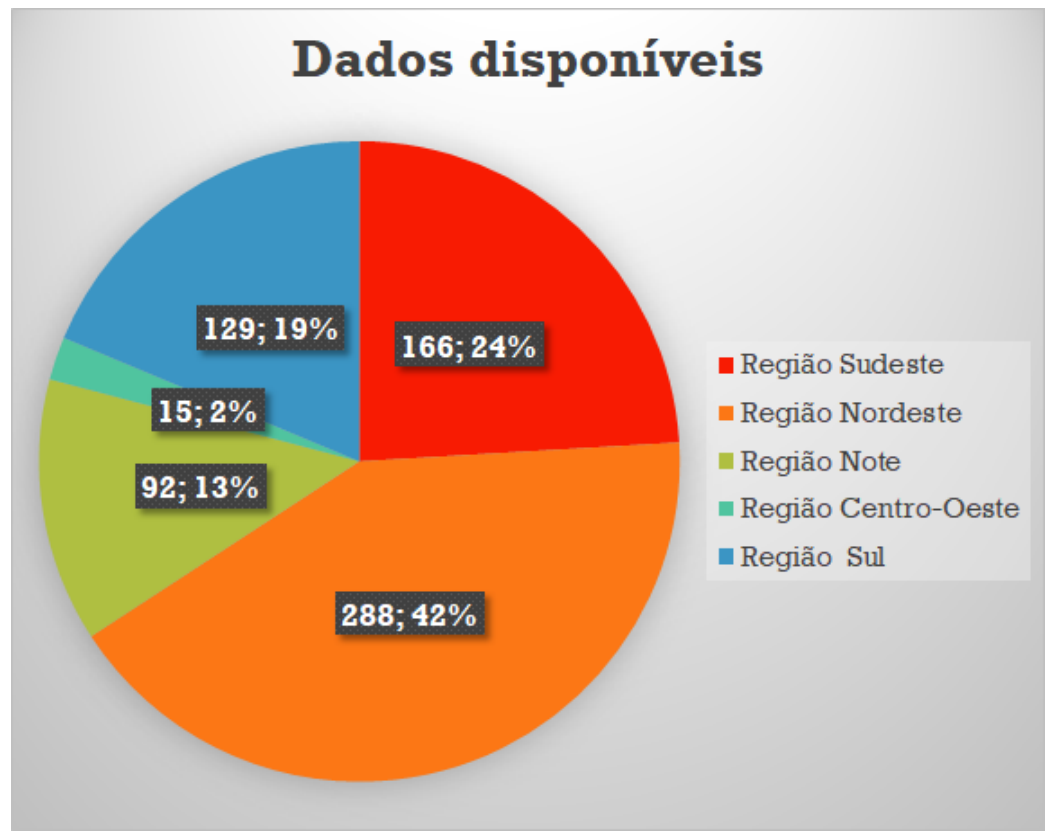

Fonte: Dados da pesquisa (2019).

Um dos objetivos desta pesquisa era localizar os Planos de Dados Abertos (PDAs) das Universidades, mas apenas duas disponibiliza no portal de dados abertos. A maioria disponibiliza no seu portal institucional e localizar nesses portais das Universidades não foi tarefa fácil. A arquitetura da informação para o acesso aos dados abertos nos portais da Universidades é considerado um fator desfavorável aos dados abertos, eles não estão visíveis, e em muitos casos, não há fácil o acesso da informação ao cidadão que entra nesses portais. Em alguns portais é preciso ir ao buscador para localizar, em outros são necessários vários cliques para chegar ao Plano de Dados Abertos com as respectivas informações ou ao link dos dados. Sem dúvidas o cidadão comum que tem pouco conhecimento sobre busca ou sobre assunto relacionado, com toda certeza não vai localizar essa informação.

Alguns PDAs são encontrados na barra inferior do portal da Instituição ou na aba "Transparência" em outros na aba "Acesso a Informação", em outros "Portal de dados abertos", ainda em "Informação" em outros "Documentos" 
em outros "Serviço de informação" em outro "Serviços" em outro "Acesso fácil" e uma universidade somente pelo buscador o documento foi encontrado, não havia indicação em nenhum dos caminho citados.

\section{Conclusão}

O Portal de Dados Abertos Governamental tem como objetivo de agrupar num único local todas as informações produzidas pelas instituições públicas federais, as Universidades que são as grandes fontes produtoras de informação científica ainda não aderiram completamente a esta ideia, tal como observamos. No entanto, esta pesquisa identificou que aproximadamente $42 \%$ da universidades já iniciaram o processo de divulgação de seus dados.

Alguns fatores relacionados à informação nos chamaram a atenção: i) não há padronização de entrada de dados, cada instituição adota o termo que lhe é mais favorável ou o que já utiliza em seus bancos individuais. ii) Conjuntos de dados são subdivididos e apresentados em separados dando a impressão que aquela instituição tem mais conjuntos disponibilizados. iii) Os "dados abertos", deste portal se aplicam tanto a dados em formulários brutos e/ ou processados, eles não oferecem insights completos sobre quais dados são, eles se concentram mais na ideia da abertura e disponibilidade para possível reutilização. Portanto, o que compreende um conjunto de dados do governo ainda é uma discussão aberta e o entendimento do que é o EGD varia e ainda está em construção.

Uma proposta deste estudo era encontrar informações relacionadas a Ciência Aberta mas, não foi possível localizar nos PDAs qualquer informação que remetesse para o avanço das instituições para além dos Dados Abertos até atingir a Ciência Aberta.

O que sabemos é que a informação do setor público é um recurso estratégico, com grande potencial para vários setores que podem ser beneficiários, como agências do setor público, empresas privadas, instituições acadêmicas, cidadãos e organizações civis. Mas nos parece que os agentes do governo brasileiro ainda estão agindo de forma descoordenada e os produtos que esses dados abertos poderiam gerar ainda não alcançaram o seu potencial. Quando se trata do cidadão a expectativa é que os dados do governo aberto permitam a participação pública e o envolvimento social na elaboração de respostas às necessidades públicas para parceria e coprodução e coparticipação em serviços e produtos para ser aplicado para o coletivo, no entanto isto também ainda não é algo que estamos divulgando como processos em evidência, aqui cabe uma pesquisa específica para esta constatação.

Os dados abertos do governo podem estimular o mercado competitivo, por exemplo, oferecendo serviços ao setor público. As inovações oferecem oportunidade de desenvolver serviços mais ágeis e direcionados às necessidades dos usuários do que aqueles desenvolvidos internamente pelos governos. Como exemplo, oferta de serviços de digitalização, repositórios digitais agregadores de informação. Na área da Ciência da Informação este se apresenta como um nicho de mercado e que só se abriu porque a esses serviços se ampliaram no setor público e os órgão não estavam preparados para atuar e o mercado observou e se apropriou dessa informação para oferecer esse serviço ao referido setor.

Percebe-se que as Universidades ainda estão se organizando para atender a Política de Dados Abertos, essa conclusão se deve ao fato de apenas $42 \%$ delas já estão com alguns dos seus dados publicados, a grande maioria apresenta menos de dez conjunto de dados. Outro fator que corrobora com essa constatação são a validade dos PDCs a maioria foi construído em 2018 com validade até 2020, apenas três universidades publicaram seus dados desde 2016. Cada PDA tem um cronograma de divulgação dos dados, mas que em alguns casos esse cronograma está atrasado ou com falta de informação que já deveriam ser disponibilizadas.

Por fim, como o principal produtor de informações e dados do setor público, o governo continua sendo a única organização legítima, democrática e responsável em atuar plenamente no interesse de toda a sociedade ao fornecer dados de qualidade. Melhorar a infraestrutura que seja confiável e acessível ao público, fazer consulta pública para identificar que dados são relevantes e aumentar a liberação de dados em formatos que permitem e promovem a reutilização, são caminhos que o governo aberto deve seguir, uma vez que, nos últimos anos a sociedade vem exigindo maior transparência do Estado e vem ganhando novas fronteiras no Brasil. 


\section{Bibliografias}

ALBAGLI, S. Ciência Aberta em questão. SEMINÁRIO INTERNACIONAL, OFICINAS E ENCONTRO DO GRUPO DE TRABALHO EM CIÊNCIA ABERTA 18 a 22 de agosto de 2014, Rio de Janeiro, Brasil. Anais... Rio de janeiro, 2014. Disponível em: http://www. cienciaaberta.net/encontro2014/

ALBAGLI, S; CLINIO, A.; RAYCHTOCK, S. Ciência Aberta: correntes interpretativas e tipos de ação. Liinc em Revista, v.10, n. 2, p.434-450, 2014. Disponível em: http://revista.ibict.br/liinc/article/view/3593/3072. Acesso em: 09 jan 2019.

ALBAGLI, S.; MACIEL, M. L.; HANNUD, A. A. (Org).Ciência aberta, questões abertas, Brasília: IBICT; Rio de Janeiro: UNIRIO, 2015. Disponível em: https://www.academia.edu/31088405/Ci\%C3\%AAncia aberta quest $\%$ C3\%B5es abertas

ARAÚJO, D. B.; AGUIAR, E. L. Dados governamentais abertos como ferramenta de participação social e aproximação entre governo e sociedade. CONGRESSO CONSAD DA GESTÃO PÚBICA, 6, 2014. Anais ... 2014. Brasília, 2014.

BRASIL. Decreto de 3 de abril de 2000. Institui grupo de trabalho interministerial para examinar e propor políticas, diretrizes e normas relacionadas com as novas formas eletrônicas de interação. Brasília, 2000. Disponível em: http://www. planalto.gov.br/ccivil 03/DNN/2000/Dnn8917.htm. Acesso em: 09 jan 2019.

BRASIL. Governo Eletrônico. Brasília, 2018a. Disponível em: https://www.governodigital.gov.br/EGD/historico-1/ historico.. Acesso em: 15 dez 2018.

BRASIL. Ministério da Transparência e Controladoria-Geral da União. $4^{\circ}$ Plano de Ação Nacional em Governo Aberto. Brasília, 2018b. disponível em: http://governoaberto.cgu.gov.br/no-brasil/planos-de-acao-1/copy of 30plano-de-aca o-brasileiro/4o-plano-de-acao-nacional portugues.pdf. acesso em: 09 jan 2019.

BRASIL. Controladoria-Geral da União - CGU. Portal da Transparência Pública: dados abertos. Brasília, Brasília, 2019. Disponível em: <http://www3.transparência. gov.br/>. Acesso em: 26 fev 2019.

BREITMAN, K. et al. Open Government Data in Brazil. Rio de Janeiro: PUC-Rio, 2012. Disponível em: http:// www-di.inf.puc-rio.br/ casanova/Publications/Papers/2012-Papers/2012-IEEE-IS-OGD in Brazil.pdf. acesso em: 26 jan 2019.

DINIZ, E. H. et al. O governo eletrônico no Brasil: perspectiva histórica a partir de um modelo estruturado de análise. RAP, Rio de Janeiro, v.43, n.1, p. 23-48, jan./fev, 2009. Acesso em: 09 jan 2019.

FUNDAÇÃO OSWALDO CRUZ - FIOCRUZ. Panorama Histórico da Ciência Aberta. Curso Formação Modular Ciência Aberta. Rio de Janeiro, 2019. (Curso 2.) Disponível em: https://campusvirtual.fiocruz.br/gestordecursos/ hotsite/panorama-ciencia-aberta. Acesso em jan 2019.

GOLDSTEIN, B.; DYSON, L. (Ed.). Beyond Transparency: Open Data and the Future of Civic Innovation. San Francisco: Code For America Press, 2013.

KLEIN,R. H.; LUCIANO, E. M.; MACADAR, M. A. Grau de transparência de dados abertos governamentais do site dados.rs.gov.br. E\&G Economia e Gestão, Belo Horizonte, v. 15, n. 41, out./dez, 2015. Disponível em: http://repositorio.pucrs.br/dspace/bitstream/10923/10052/2/Grau de Transparencia de Dados Abertos Governamentais do site dados rs gov br.pdf. Acesso em: 20 fev 2019.

LAFUENTE, A.; ESTALELLA, A. Modos de ciência: pública, aberta y comúm, Ciência aberta, questões abertas, Brasília: IBICT; Rio de Janeiro: UNIRIO, p. 27-59, 2015.

NIELSEN, M. A. Reinventing Discovery: The New Era of Networked Science. Princeton, 2011.

OGP BRAZIL HOME . Brazil: The following text was contributed by the Government of Brazil. 2019. Disponível em: https://www.opengovpartnership.org/countries/brazil. Acesso em: jan 2019. 
OREGON STATE UNIVERSITY . Serviços de Dados de Pesquisa: Data Papers \& Journals. Disponível em: https:// quides.library.oregonstate.edu/research-data-services/data-management-data-papers-journals. Acesso em: 06 fev 2019.

ORGANIZAÇÃO DA NAÇÕES UNIDAS (ONU). Agenda 3023:Transformando Nosso Mundo: A Agenda 2030 para o Desenvolvimento Sustentável. (s,d). Disponível em: https://nacoesunidas.org/pos2015/agenda2030/. Acesso em: Acesso em: 09 de janeiro, 2019.

SANTOS, P. X. Ciência Aberta Gestão e abertura de dados para pesquisa: o que é, para que e como? Rio de Janeiro: FIOCRUZ/VPEIC, 2018. 37 p. https://www.arca.fiocruz.br/handle/icict/28706

SANTOS, P. X. (Coord.). Livro Verde - Ciência aberta e dados abertos: mapeamento e análise de políticas, infraestruturas e estratégias em perspectiva nacional e internacional. Rio de Janeiro: Fiocruz, 2017. 141 p. Disponível em: https://www.arca.fiocruz.br/handle/icict/28706

SILVA JÚNIOR, A. da O perfil ideal do contador público frente à responsabilidade social. Revista Economia \& Gestão, v. 1, n. 2, 2008

TRIBUNAL DE CONTAS DA UNIÃO - TCU. (2015). Secretaria de Fiscalização de Tecnologia da Informação. 5 motivos para a abertura de dados na Administração Pública. Brasília, 2015. Disponível em: https://portal.tcu.gov.br/ biblioteca-digital/cinco-motivos-para-a-abertura-de-dados-na-administracao-publica.htm. Acesso em: 26 fev 2019.

UBALDI, B. Open Government Data: Towards Empirical Analysis of Open Government Data Initiatives. OECD Working Papers on Public Governance. 2013. OECD Publishing. n 22. http://dx.doi.org/10.1787/5k46bj4f03s7-en. Disponível em: https://www.espap.qov.pt/Documents/espap lab/2015 04 Open Government Data.pdf. Acesso em: 09 jan 2019.

VICTORINO, M. C. et al. Uma proposta de ecossistema de big data para a análise de dados abertos governamentais conectados. Inf. \& soc.:Est., João Pessoa, v.27, n.1, p. 225-242, jan./abr. 2017.

VIEIRA, D. I.; ALVARO, A. "A centralized platform of open government data as support to applications in the smart cities context", International Journal of Web Information Systems, v. 14 Issue: 1, p.2-28, 2018. https://doi. org/10.1108/IJWIS-05-2017-0045

WOELFLE, M.; OLLIARO, P.; TODD, M. H. Open science is a research accelerator, NATURE Chemistry, v. 3, p. 745-748, 2011 Disponível em: https://www.nature.com/articles/nchem.1149.pdf?origin=ppub. Acesso em: 04 jun 2019. 


\section{Dados dos autores}

Ana Cristina Gomes Santos

Universidade Federal de Rural de Amazônia, Belém, Pará, Brasil

Doutoranda em Ciência da Informação da Universidade Fernando Pessoa. Mestre em Ciência da Informação pelo IBICT/UFRJ. Graduada em Biblioteconomia pela Universidade Federal do Pará. Especialista em Biblioteca Universitária pela UFPA. Servidora pública vinculada a Universidade Federal Rural da Amazônia atuando na gestão da Biblioteca Universitária. Com experiencia em atendimento ao público, gerencia de unidade de informação, atividades comunitárias com a prática de incentivo a leitura e a informação; Membro do Nucleo de Educação e Diversidade na Amazônia (NEDAM).

gomess_cristina@yahoo.com.br

\section{Judite Antonieta Gonçalves de Freitas}

Doutora em no ramo de conhecimento História na Faculdade de Letras daUniversidade do Porto. Mestra em História Medieval na Faculdade de Letras da Universidade do Porto. Docente na categoria de Professora Auxiliar da FCHS / Universidade Fernando Pessoa (UFP) desde Outubro de 1999. Docente na categoria de Professora Associada da FCHS / UniversidadeFernando Pessoa desde Outubro de 2003. Passou a categoria catedrática desde 2010.

jfreitas@ufp.edu.pt

Received: 2019-06-11

Accepted: 2021-07-31

\section{(cc) BY}

This work is licensed under a Creative Commons Attribution 4.0 United States License.

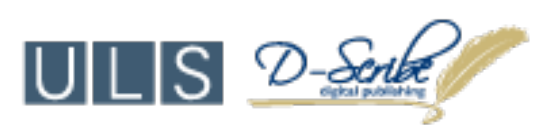

This journal is published by the University Library System of the University of Pittsburgh as part of its D-Scribe Digital Publishing Program and is cosponsored by the University of Pittsburgh Press 